\title{
ACIDENTE CROTÁLICO NA INFÂNCIA: ASPECTOS CLÍNICOS, LABORATORIAIS, EPIDEMIOLÓGICOS E ABORDAGEM TERAPÊUTICA.
}

\author{
Palmira Cupo, Marisa M. Azevedo Marques e Sylvia Evelyn Hering
}

\begin{abstract}
Foram atendidas no Hospital das Clínicas da Faculdade de Medicina de Ribeiräo Preto/USP, durante os anos de 1980 a 1989, 21 criancas vítimas de acidente crotálico, 16 das quais apresentaram sinais clínicos de envenenamento grave à admissão e 5 , de envenenamento moderado. Quatro pacientes (20\%) desenvolveram necrose tubular aguda, dois dos quais necessitaram métodos dialíticos. Um paciente (5\%) foi a óbito no 13.o dia do acidente, após intercorrências graves, como hemorragia digestiva e insuficiência respiratória aguda. São apresentadas as características clínicas, laboratoriais e epidemiológicas do acidente crotálico nesses pacientes, enfatizando os conhecimentos atuais sobre a fisiopatologia do envenenamento por Crotalus durissus terrificus. Ao mesmo tempo, pretendeu-se contribuir para a correta abordagem terapêutica, no que diz respeito ao emprego adequado do soro antiveneno e à prevenção da necrose tubular aguda, a mais séria e grave complicação do acidente crotálico.
\end{abstract}

Palavras-chaves: Crotalus durissus terrificus. Acidentes ofidicos em criancas. Rabdomiólise. Mioglobinúria.

Os acidentes provocados por serpentes do gênero Crotalus no Brasil, revestem-se de importância não só pela sua alta incidência em determinadas regiões, como pela sua potencialidade em produzir quadros graves e até mesmo fatais, acrescentando-se ainda que os acidentes acometem principalmente indivíduos na fase produtiva da vida.

Existem seis espécies identificadas, que se distribuem de maneira irregular pelo território nacional, predominando os acidentes na regiāo sudeste do país. No Estado de São Paulo, a espécie mais comumente encontrada é a Crotalus durissus terrificus.

Os acidentes crotálicos são menos frequentes que os botrópicos. Dados do Instituto Butantan (Hospital Vital Brazil, 1966-1977) e a Estatística Anual de 1989, elaborada pelo Ministério da Saúde, revelam que 8 a $10 \%$ dos acidentes por ofidios venenosos, são causados por cascáveis. Já na região de Ribeirão Preto (dados fornecidos pelo Centro de Intoxicação do Hospital das Clínicas) e de Botucatu ${ }^{9}$, esse percentual chega a $20-25 \%$.

\footnotetext{
Departamentos de Puericultura e Pediatria e Clínica Médica da Faculdade de Medicina de Ribeirão Preto, Universidade de São Paulo, Ribeirão Preto, SP.
}

Endereço para correspondência: Dra. Palmira Cupo. Depto Pueric. e Pediatria Fac'Med Rib. PretorUSP 14049 Ribeirão Preto, SP.

Recebido para publicação em 09/10/90.
Apesar da relativa frequência do ofidismo em várias regiões brasileiras, poucos são os relatos sobre o assunto, e, em se tratando de crianças, a literatura é ainda mais escassa.

Na maioria das vezes, o paciente picado chega até o profissional de saúde sem a cobra causadora do acidente e, quando a traz, a mesma se encontra de tal modo esmagada, que não permite identificação. É necessário então, com os dados clínicos existentes reconhecer qual o tipo de serpente envolvida no acidente, a fim de o mais rapidamente possivel instituir o soro antiveneno (SAV). Essa identificação é possível, desde que se tenha conhecimento da composição dos diferentes venenos ofidicos e dos efeitos que suas atividades produzem no organismo.

O veneno crotálico, até o início da década de 1980 , era referido como possuindo atividades principais do tipo hemolítica e neurotóxica ${ }^{36}$, sendo a mais grave complicação nos acidentes humanos, a insuficiência renal com necrose tubular aguda (NTA), cuja patogenia foi sempre interpretada como decorrente do efeito hemolítico da peçonha associado ou não ao efeito nefrotóxico direto ${ }^{3}$.

Estudos realizados a partir de 1982, em pacientes vítimas de acidentes crotálico, utilizando dados de observação clínica, laboratorial e de biópsia muscular efetuada em membro contralateral à picada, demonstraram a ação miotóxica sistêmica da peçonha de Crotalus durissus terrificus, que se caracteriza pela agressão às fibras musculares esqueléticas $^{6} 781112212837$.

Posteriormente, em 1986, foi identificada no veneno a existência de enzima com atividade do tipo trombina ${ }^{32}$, que exerce efeito coagulante sobre o 
plasma in vitro, podendo provocar consumo de fibrinogênio, havendo relatos de afibrinogenemia e incoagulabilidade sanguinea com prolongamento do tempo de coagulação (TC), sem consumo de plaquetas 12 .

Em 1987, foi descartada a atividade hemolitica do veneno crotálico ${ }^{8}$, supostamente responsável pela coloração escura da urina, através de exames laboratoriais específicos (dosagens de hemoglobina e haptoglobina séricas e ausência de hemoglobinúria).

A partir desses dados, a peçonha de Crotalus durissus terrificus tem sido descrita atualmente como possuindo atividades principais do tipo neurotóxica e miotóxica sistêmica, além da ação coagulante tipo trombina, a elas sendo atribuidas as manifestações clínicas encontradas nos acidentes humanos. Dado que a peçonha é desprovida de atividade proteolitica, no local da picada observa-se apenas as marcas das presas, com edema e/ou eritema discretos ou ausentes.

O objetivo do presente trabalho é descrever as caracteristicas clínicas, laboratoriais e epidemiológicas do acidente crotálico em 21 crianças atendidas no Hospital das Clínicas da Faculdade de Medicina de Ribeirão Preto (HC-FMRP/USP) enfatizando os conhecimentos atuais sobre a fisiopatologia do envenenamento por Crotalus durissus terrificus. Ao mesmo tempo, pretende-se contribuir para a correta abordagem terapêutica desses pacientes, no que diz respeito ao emprego adequado do $\mathrm{SAV}$ e à prevenção da NTA, a mais séria e grave complicação do acidente crotálico.

\section{MATERIAL E MÉTODOS}

Foram atendidos no HC-FMRP/USP, durante o período de 1980 a 1989, 21 pacientes com idade compreendida entre 3 e 15 anos (Tabela 1), vitimas de acidente por $C$. durissus terrificus, todos apresentando sinais clínicos de envenenamento à admissão.

Tabela 1 - Classificação dos pacientes quanto a faixa etária e sexo.

\begin{tabular}{lcc}
\hline $\begin{array}{l}\text { Idade } \\
\text { (anos) }\end{array}$ & Masculino & Feminino \\
\hline Até 5 & 0 & 5 \\
6 a 10 & 6 & 3 \\
11 a 15 & 7 & 0 \\
\hline Total & 13 & 8 \\
\hline
\end{tabular}

Os acidentes foram classificados como moderados, quando havia ptose palpebral e/ou alterações visuais e urina de cor clara ou pouco alterada; como graves, quando a esses sinais e sintomas se somaram urina escura, mialgia generalizada e comprometimento do estado geral (Tabela 2).
Todos os pacientes eram provenientes de zona rural; em 11 casos o acidente ocorreu durante o lazer e em 10, foi caracterizado durante atividade profissional.

A cobra causadora do acidente foi capturada e identificada como $C$. durissus terrificus em 10 casos; em 6, havia a informação da criança ou dos familiares sobre o ruído do guizo, e, nos 5 restantes, o diagnóstico baseou-se no quadro clínico. Uma mesma cobra esteve envolvida em dois acidentes, acometendo duas crianças que caminhavam próximas (ambas classificadas como casos graves).

As picadas predominaram no periodo diurno (6 às 12 horas, 7 casos e 13 à 18 horas, 10) e ocorreram principalmente nos membros inferiores (pé em 11 casos e perna em 9).

Os acidentes se distribuíram por todos os meses do ano, sendo que $50 \%$ deles ocorreram nos meses de março a maio.

Garrote foi utilizado por 7 pacientes e em 1 caso, há relato de haver sido colocado urina sobre o local picado.

A maioria dos pacientes procurou 0 HC-FMRP/USP dentro das primeiras 6 horas após acidente e em 7 crianças, o SAV foi administrado nas primeiras 3 horas (Tabela 6). Atendimento médico em hospital de origem foi procurado por 4 pacientes, todos encaminhados tardiamente ao nosso hospital $(10,20 \mathrm{e}$ 2 após 24 horas da picada).

A atividade miotóxica sistêmica do veneno crotálico foi avaliada através das dosagens seriadas de creatinoquinase $(C K)$ e lactatodesidrogenase $(L D)$ totais e de suas isoenzimas e pela deteç̧ão de mioglobina em soro e urina, através da imunodifusão desses materiais contra soro antimioglobina humano (Behringwerke). Em dois pacientes foi realizada biópsia muscular em membro contralateral à picada, após consentimento prévio dos pais.

As dosagens de $\mathrm{CK}$ (ativadas com $\mathrm{N}$-acetilcisteína) e $\mathrm{LD}$ total foram determinadas a $25^{\circ} \mathrm{C}$, utilizando-se kits comerciais (Merck - testes UV optimizados). As respectivas isoenzimas foram identificadas por eletroforese em gel de agarose e quantificadas por densitometria fluorescente (Sistema Fluorométrico Corning), sendo tomados todos os cuidados necessários a essa metodologia 3339 .

Em alguns pacientes foram realizadas dosagens seriadas de hemoglobina sanguínea e sérica e da haptoglobina (ensaio nefelométrico-Beckman); a pesquisa de hemoglobina na urina foi realizada através de imunodifusão contra soro anti-hemoglobina humano (Miles-Yeda).

A avaliação da coagulação sanguinea foi realizada através da determinação do tempo de coagulação (TC). 
Cupo P, Marques MMA, Hering SE. Acidente crotálico na infância: aspectos clínicos, laboratoriais, epidemiológicos e abordagem terapèutica. Revista da Sociedade Brasileira de Medicina Tropical 24: 87-96, abr-jun, 1991

Tabela 2 - Acidente crotálico: classificação quanto à gravidade e número de ampolas a serem administradas*.

\begin{tabular}{|c|c|c|c|c|c|c|}
\hline $\begin{array}{l}\text { Manifestacöes } \\
\text { e tratamento } \\
\begin{array}{l}\text { Gravidade } \\
\text { (inicial) }\end{array}\end{array}$ & $\begin{array}{c}\begin{array}{c}\text { Facies } \\
\text { miastênica }\end{array} \\
\text { Visão } \\
\text { turva }\end{array}$ & Mialgia & $\begin{array}{l}\text { Urina } \\
\text { escura }\end{array}$ & $\begin{array}{l}\text { Oligúria } \\
\text { ou } \\
\text { Anúria }\end{array}$ & $\mathrm{TC}^{* *}$ & $\begin{array}{c}\text { No } \\
\text { ampolas } \\
\text { SAV/Via }\end{array}$ \\
\hline Moderada & $\begin{array}{c}\text { discreta } \\
\text { ou } \\
\text { ausente }\end{array}$ & $\begin{array}{l}\text { discreta } \\
\text { ou } \\
\text { ausente }\end{array}$ & $\begin{array}{c}\text { pouco } \\
\text { evidente } \\
\text { ou } \\
\text { ausente }\end{array}$ & ausente & $\begin{array}{l}\text { geral. } \\
\text { normal }\end{array}$ & $10 /$ iv \\
\hline Grave & presente & presente & presente & $\begin{array}{c}\text { presente } \\
\text { ou } \\
\text { ausente }\end{array}$ & $\begin{array}{c}\text { normal } \\
\text { ou } \\
\text { alter. }\end{array}$ & $20 /$ iv \\
\hline
\end{tabular}

- Quadro elaborado pelo grupo técnico do Ministério da Saúde do Brasil para padronização do diagnóstico e terapêutica dos acidentes ofídicos1986.

- TC = normal até 9 minutos; prolongado de 10 a 30 minutos; incoagulável, acima de 30 minutos.

Em seis pacientes foram realizados eletrocardiogramas (ECG) seriados, acompanhando as dosagens enzimáticas e quatro deles foram submetidos à ecocardiografia uni e bidimensional, acoplada com Doppler, para avaliação da função cardiaca.

\section{RESULTADOS}

Os sinais e sintomas apresentados pelos pacientes à admissão estão referidos na Tabela 3. Verifica-se que com exceção de 1 paciente, todos os demais apresentaram ptose palpebral bilateral, assimétrica em 5 deles, caracterizando o facies miastênico (neurotóxico, de Rosenfeld ${ }^{36}$ ), sinal fundamental para o diagnóstico do acidente crotálico.

Tabela 3 - Caractertsticas clínicas dos pacientes à admissão.

\begin{tabular}{lrc}
\hline Sinais/Sintomas & \multicolumn{2}{c}{ Pacientes } \\
\hline Sistémicos & N. & $\%$ \\
ptose palpebral & 20 & 95,2 \\
oftalmoplegia & 20 & 95,2 \\
diplopia & 17 & 81,0 \\
sonolência & 17 & 81,0 \\
mialgia & 16 & 76,2 \\
urina escura & 15 & 71,4 \\
torpor & 12 & 57,6 \\
anisocoria & 8 & 38,1 \\
sudorese & 8 & 38,1 \\
vômitos & 8 & 38,1 \\
tremores/espasmos & & \\
$\quad$ musculares & 6 & 28,6 \\
& & \\
Locais & & 71,4 \\
edema/eritema & 15 & 47,6 \\
parestesia & 10 & 38,1 \\
dor (discreta) & 8 &
\end{tabular}

A maioria dos pacientes apresentou-se sonolenta, constatando-se estado torporoso em 50\%; tais sintomas não estiveram relacionados com o uso prévio de qualquer medicação.

A mialgia foi referida espontâneamente em 8 casos; nos demais, foi caracterizada após interrogatório, como dores pelo corpo, muitas vezes mais intensa no dorso e pescoço. Tremores e às vezes espasmos musculares, foram observados em 6 pacientes, não relacionados com a febre ou com administração do SAV.

Nenhum paciente apresentou quadro clínico de anemia ou icterícia durante a evolução, mesmo aqueles que cursaram com os quadros mais graves.

Nas primeiras horas após acidente, as crianças evoluiram com taquicardià, com manutenção dos demais sinais vitais.

Insuficiência renal aguda foi detectada em 4 pacientes e em 2 deles houve necessidade de diálise peritoneal. Uma dessas crianças foi a óbito no $13 \%$ dia de evolução, após intercorrências graves, como hemorragia digestiva e insuficiência respiratória, que levou ao uso de ventilação mecânica.

Urina escura foi detectada já à admissão em 15 pacientes; em 2 deles ela tornou-se escurecida logo nas primeiras horas e, em 4, manteve-se clara durante toda a evolução.

\section{Dados laboratoriais}

Dosagens seriadas de CK e LD total foram realizadas em 17 pacientes e, em 13 deles, foram identificadas e quantificadas as respectivas isoenzimas. $\mathrm{Na}$ Tabela 4 estão apresentadas as dosagens obtidas em 4 desses pacientes, que refletem os resultados do grupo como um todo, visto o comportamento homogêneo do conjunto, salvo variações nos valores absolutos. 
Cupo P. Marques MMA, Hering SE. Acidente crotálico na infância: aspectos clínicos, laboratoriais, epidemiológicos eabordagem terapêutica. Revista da Sociedade Brasileira de Medicina Tropical 24: 87-96, abr-jun 1991

Tabela 4 - Exames laboratoriais seqüenciais realizados nos pacientes observados.

\begin{tabular}{|c|c|c|c|c|c|c|c|c|c|}
\hline Pacientes & $\begin{array}{l}\text { Horas } \\
\text { após } \\
\text { picada }\end{array}$ & $\begin{array}{c}\text { CK* } \\
10-80 \\
\mathrm{iu} / 1\end{array}$ & $\begin{array}{c}\mathrm{CK}-\mathrm{MB}^{\circ} \\
\text { até } 5 \\
\%\end{array}$ & $\begin{array}{c}L^{\circ} \\
100-200 \\
\text { iu/ } 1\end{array}$ & $\begin{array}{l}\mathrm{LD1} \\
16-28 \\
\%\end{array}$ & $\begin{array}{c}\text { LD2 } \\
29-37 \\
\%\end{array}$ & $\begin{array}{c}\text { LD3* } \\
17-23 \\
\%\end{array}$ & $\begin{array}{c}\text { LD4* } \\
9-15 \\
\%\end{array}$ & $\begin{array}{c}\mathrm{LD5}^{*} \\
8-20 \\
\%\end{array}$ \\
\hline \multirow{5}{*}{ D.M.M. } & 2 & 37 & 0 & 164 & 26.2 & 32.2 & 23.8 & 8.8 & 9.1 \\
\hline & 4 & 97 & 0 & 128 & 20.8 & 24.8 & 20.2 & 21.6 & 12.7 \\
\hline & 18 & 765 & 14.2 & 137 & 35.1 & 31.7 & 18.5 & 8.5 & 6.2 \\
\hline & 40 & 520 & 9.8 & 228 & 34.9 & 30.2 & 17.0 & 12.0 & 5.8 \\
\hline & 60 & 245 & 0 & 210 & 33.7 & 30.6 & 15.6 & 8.1 & 12.0 \\
\hline \multirow{6}{*}{ R.A.F. } & 3 & 405 & 7.1 & 230 & 26.2 & 27.3 & 20.7 & 15.6 & 10.3 \\
\hline & 6 & 2.930 & 9.8 & 300 & 34.3 & 28.4 & 17.0 & 10.2 & 10.0 \\
\hline & 12 & 4.860 & 4.3 & 465 & 36.1 & 29.2 & 17.6 & 9.4 & 7.7 \\
\hline & 22 & 4.000 & 6.2 & 585 & 38.3 & 30.5 & 16.7 & 7.5 & 7.0 \\
\hline & 46 & 1.143 & 5.8 & 1.620 & 43.8 & 32.5 & 12.9 & 6.2 & 4.6 \\
\hline & 94 & 91 & 0 & 830 & 47.4 & 32.3 & 9.9 & 6.4 & 4.0 \\
\hline \multirow{5}{*}{ M.R. } & 3 & 10.772 & 11.6 & 301 & 36.1 & 22.9 & 14.7 & 17.1 & 9.2 \\
\hline & 9 & 25.258 & 9.1 & 614 & 43.1 & 25.4 & 12.9 & 9.4 & 9.2 \\
\hline & 18 & 37.887 & 10.8 & 1.730 & 40.4 & 30.0 & 15.4 & 7.6 & 6.6 \\
\hline & 26 & 30.459 & 10.6 & 2.918 & 37.2 & 30.7 & 15.1 & 9.3 & 7.7 \\
\hline & 40 & 17.800 & 6.8 & 3.200 & 44.8 & 34.6 & 10.8 & 3.6 & 2.2 \\
\hline \multirow{4}{*}{ D.M.S. } & 24 & 46.425 & 20.9 & 2.950 & 35.3 & 26.7 & 17.1 & 8.0 & 13.0 \\
\hline & 30 & 43.830 & 24.1 & 3.100 & 35.6 & 26.1 & 15.9 & 10.0 & 12.4 \\
\hline & 36 & 43.014 & 15.8 & 3.250 & 41.1 & 25.6 & 16.5 & 7.5 & 9.4 \\
\hline & 44 & 38.631 & 8.6 & 4.025 & 38.8 & 30.4 & 17.7 & 6.2 & 6.8 \\
\hline
\end{tabular}

- $\mathrm{CK}=$ creatinoquinase; $\mathrm{LD}=$ lactatodesidrogenase; CK-MB = isoenzima CK; LDI-5 = iscenzimas de LD.

$\mathrm{Na}$ Tabela 5 estão discriminados os demais exames laboratoriais realizados.

Aumento nos níveis sanguíneos de uréia, crea- tinina, fósforo e ácido úrico, bem como diminuição acentuada da calcemia foram detectados nos quatro pacientes que evoluíram para IRA.

Tabela 5 - Exames laboratoriais seqüenciais realizados nos pacientes picados por Crotalus durissus terrificus.

\begin{tabular}{|c|c|c|c|c|c|c|c|}
\hline \multirow{2}{*}{ Pacientes } & \multirow{2}{*}{$\begin{array}{l}\text { Horas } \\
\text { após } \\
\text { picada }\end{array}$} & \multirow{2}{*}{$\begin{array}{l}\text { TGO }^{*} \\
\text { (até 18) } \\
\text { iu/1 }\end{array}$} & \multirow{2}{*}{$\begin{array}{c}\text { TGP* } \\
\text { (até 18) } \\
\text { iu/l }\end{array}$} & \multirow{2}{*}{$\begin{array}{l}\mathbf{H b} \\
\mathbf{g} \%\end{array}$} & \multirow{2}{*}{$\begin{array}{l}\mathrm{TC}^{*} \\
\text { min. }\end{array}$} & \multicolumn{2}{|c|}{ Urina } \\
\hline & & & & & & $\mathbf{M g b}$ & $\mathrm{Hb}$ \\
\hline \multirow{4}{*}{ D.M.M. } & 2 & 13 & 12 & 10,9 & 8 & + & - \\
\hline & 4 & 18 & 15 & 10,7 & 8 & + & - \\
\hline & 18 & 37 & 22 & 10,5 & 6 & + & - \\
\hline & 40 & 35 & 18 & 10,8 & nnt* & - & \\
\hline \multirow{5}{*}{ M.R } & 3 & 230 & 20 & 13.8 & $>60$ & + & - \\
\hline & 9 & 420 & 58 & 13,5 & 10 & + & - \\
\hline & 18 & 654 & 88 & 13,2 & 8 & + & - \\
\hline & 26 & 890 & 144 & 13,4 & 8 & + & - \\
\hline & 40 & 566 & 117 & 13,2 & $\mathbf{n r}$ & - & - \\
\hline \multirow{4}{*}{ J.R } & 3 & 240 & 30 & 13,2 & $>40$ & + & - \\
\hline & 9 & 580 & 75 & 13.6 & 8 & + & - \\
\hline & 26 & 1327 & 370 & 13,1 & 5 & + & - \\
\hline & 48 & 660 & 198 & 13,3 & $\mathrm{nr}$ & - & - \\
\hline \multirow{3}{*}{ D.M.S. } & 24 & 530 & 188 & 11,6 & $>60$ & + & - \\
\hline & 30 & 611 & $\mathrm{nr}$ & 11,8 & 9 & + & - \\
\hline & 36 & 580 & 160 & 11,5 & 8 & + & - \\
\hline
\end{tabular}

TGO = transaminase glutàmico-oxalacetica; $\mathrm{TGP}=$ transaminase glutamico-pirúvica; $\mathrm{Hb}=$ hemoglobina; $\mathrm{TC}=$ tempode congulaça; $\mathrm{Mgb}=$ mioglobina

- Náo realizado. 
Cupo P. Marques MMA, Hering SE. Acidente crotálico na infância: aspectos clínicos, laboratoriais, epidemiológicos e abordagem terapèutica. Revista da Sociedade Brasileira de Medicina Tropical 24: 87-96, abr-jun, 1991

O TC foi realizado em 14 pacientes. Incoagulabilidade sanguínea (TC $>30$ minutos) foi verificada em 9, todos com envenenamento grave; TC normal ( $<10$ minutos) foi observado nos 5 pacientes restantes, 3 classificados como acidentes moderados e 2 , como graves.

Nunca foi verificada presença de hemólise nas várias amostras de soro e/ou plasma dos pacientes. Pesquisa de hemoglobina urinária, realizada em 15 pacientes, foi negativa.

Presença de mioglobina em soro e urina foi detectada em todos os pacientes, mesmo naqueles que evoluiram com urina clara.

As alterações de ECG observadas foram: taquicardia e arritmia sinusal, alterações discretas da repolarização ventricular, ondas $T$ apiculadas e presença ocasional de onda $U^{12}$.

Os achados de ecocardiografia foram: câmaras cardiacas de dimensões normais, ausência de efusão pericárdica, função sistólica do ventrículo esquerdo normal, fluxo transmitral normal e ausência de alterações regionais de motilidade 12 .

\section{Dados anátomo-patológicos}

A biópsia muscular, realizada em 2 pacientes, em membro inferior contralateral à picada, mostrou à microscopia ótica, fibras musculares necróticas intercaladas com fibras aparentemente normais.

A microscopia eletrônica revelou focos de mionecrose com desintegraçáo miofibrilar, desorganiza- ção e lise de miofilamentos, perda de estriações transversais, dilatação do retículo sarcoplasmático, formação de bandas de contração e edema mitocondrial, ao lado de fibras intactas no mesmo músculo 6 .

Os dados de necrópsia, referentes a um paciente, foram: Rins: tumefeitos e congestos, com degeneração e necrose de células epiteliais de revestimento dos túbulos e ruptura da membrana basal (tubulorexis); distribuição irregular de cilindros contendo pigmento heme no interior dos túbulos. Coração: sinais de hipertrofia moderada de fibras cardiacas, com edema intersticial. Fígado: esteatose hepática moderada. Encéfalo: edema cerebral. Trato Gastrintestinal: erosões múltiplas em esôfago, estômago e duodeno. Pulmões: broncopneumonia confluente bilateral. Músculo esquelético: rabdomiólise.

\section{DISCUSSÃO}

Pelos dados apresentados, observa-se que todos os pacientes à admissão, apresentavam sinais clínicos de envenenamento crotálico; o acidente foi considerado moderado em 5 casos e grave nos 16 restantes.

Os dados da Tabela 6 permitem inferir que a gravidade e a evolução clínica dos pacientes estiveram relacionadas com o tempo decorrido entre a picada e a administração da SAV específico, em dose e via adequadas. Verifica-se que praticamente todos os pacientes que receberam SAV após a 3: hora do acidente, foram classificados como graves. Os quatro pacientes que desenvolveram NTA e o único óbito

Tabela 6 - Tempo decorrido entre o acidente e a administração de antiveneno no HC-FMRP/USP, classificação quanto à gravidade e complicaçóes clínicas dos pacientes picados por Crotalus durissus terrififus.

\begin{tabular}{lcccccc}
\hline Tempo & No de & \multicolumn{2}{c}{ Gravidade } & & Complicaçóes & Obito \\
\hline pacientes & Moderada & Grave & NTA $^{*}$ & IRA & Ob \\
\hline 3 a 6 horas & 7 & 4 & 3 & 0 & 0 & 0 \\
$>$ 6 horas & 10 & 1 & 9 & 0 & 0 & 0 \\
\hline
\end{tabular}

- NTA = necrose tubular aguda; * IRA = insuficiència respiratória aguda

verificado, só receberam soroterapia adequada tardiamente, embora tivessem procurado assistência médica na cidade de origem nas 3 primeiras horas após picada. Um dos quatro pacientes chegou ao nosso hospital 24 horas após acidente, sem diagnóstico e outros chegaram após 10, 20 e 24 horas, medicados com SAV em dose e via inadequadas.

Os sinais de rabdomiólise detectados nas biópsias musculares podem ser inferidos clinicamente pela queixa de mialgia e urina escura, associados ao aumento de CK e LD séricos e pela presença de mioglobina em soro e urina, conforme revelam os dados das Tabelas 4 e 5.

As crianças que receberam SAV mais precocemente apresentaram os menores valores enzimáticos e é interessante ressaltar que a mioglobina foi detectada em amostras de soro e urina clara, mesmo antes do aumento das enzimas séricas.

A ausência de coloração rósea do plasma na vigência de urina escura e a não detecção de anemia e 
Cupo P, Marques MMA, Hering SE. Acidente crotálico na infância: aspectos clínicos, laboratoriais, epidemiológicos e abordagem terapêutica. Revista da Sociedade Brasileira de Medicina Tropical 24: 87-96, abr-jun, 1991

icterícia, sinais esses nunca referidos na literatura, mesmo naqueles casos de evolução mais grave, descartam a suposta existência de hemólise no acidente crotálico humano. A manutenção dos niveis de hemoglobina sanguinea, os valores normais da haptoglobina, dosada em 3 pacientes, e a não deteç̧ão de hemoglobina na urina, pesquisada através de imunodifusão contra soro anti-hemoglobina humana, corroboram a inexistência de hemólise.

Convém ressaltar que o teste da benzidina bem como as tiras reagentes para uroanálise, dão resultados positivos na presença do grupo heme, não diferenciando portanto se o pigmento responsável pela coloração da urina é a hemoglobina ou a mioglobina. Cuidado também deve ser tomado com o uso de sondas vesicais, que, podendo causar traumatismo e consequente hematúria, podem falsear os resultados.

Observando-se os dados da Tabela 4 verifica-se que o aumento de CK e LD total apresentou comportamento bastante definido: a CK aumenta precocemente, atingindo pico máximo nas primeiras 24 horas após acidente e a LD começa a subir mais tardiamente, com valores extremos 48 a 72 horas após picada, mantendo-se elevada por mais tempo.

Os valores das isoenzimas CK-MB e LD1, denominadas frações cardíacas, também aumentam já nas primeiras horas após acidente, atingindo niveis tais que ultrapassam aqueles considerados limitrofes para o infarto agudo do miocárdio (IAM), ou seja, maior que $5 \%$ para a CK-MB 2733 e LD1/LD2 maior que $0,76^{24} 27$ ou maior que 148 , adotando-se os valores de referência para eletroforese.

A fração CK-MB oriunda da musculatura cardíaca representa $20 \%$ da atividade de CK total 262946 , enquanto aquela proveniente da musculatura esquelética corresponde a 1 - $6 \%$ do total de $\mathrm{CK}^{45} 47$, variando essas porcentagens com os diferentes músculos do corpo e com seu conteúdo em fibras tipo I e II 16 .

Em relação às isoenzimas de $\mathrm{LD}$, a maioria dos tecidos possui as cinco frações, predominando a fraç̃ao LD1 e, em menor grau, a fração LD2, no miocárdio, e a fração LD5 no figado e musculatura esquelética. Outras fontes não despreziveis de LD1 são as hemácias, rins, cérebro, pâncreas e hemólise in vivo $e$ in vitro 3334 .

A cinética de CK e LD total e principalmente de suas isoenzimas CK-MB e LD1, associada aos dados clínicos e de ECG, é considerada atualmente um dos exames bioquímicos mais sensiveis para o diagnóstico de certeza do infarto agudo do miocárdio 2734 . Em nossos pacientes observa-se que apesar dos dados de enzimas e isoenzimas sugerirem comprometimento do miocárdio, os dados clínicos; de ECG e de ecocardiografia não demonstram qualquer envolvimento cardíaco.

Na maioria dos relatos clínicos existentes sobre acidentes por serpentes cuja peçonha possui atividade miotóxica sistêmica, não há descrição de qualquer envolvimento cardíaco 1820283144 .

Com exceção dos dados de necrópsia de pacites vitima de acidente fatal por Pseudechis australis ${ }^{38}$ onde há descrição de necrose de fibras cardiacas, os demais relatos anátomo-patológicos desse tipo de pacientes, revelam ausência ou relativa pobreza de alterações no miocárdio 222330 , quando comparadas com as extensas lesões de musculatura esquelética 23 30 , o mesmo tendo ocorrido com os achados de necrópsia de nosso paciente, cujo óbito se deu no 13. dia após acidente.

Recentemente, em nosso meio, foi relatada lesão miocárdica em acidente fatal por $C$. durissus terrificus $^{42}$. No entanto, os dados disponíveis no relato demonstram que houve um atraso entre o aparecimento das manifestações eletrocardiográficas sugestivas de comprometimento cardíaco e a inoculação do veneno crotálico, 3 dias antes. Diante de nossas observações de que a agressão ao músculo esquelético é imediata, com excreção de mioglobina já nas primeiras duas horas após picada, seria de se esperar que o mesmo ocorresse em relação ao músculo cardíaco. $O$ padrão enzimático relatado $(\mathrm{CK}=81000$ $\mathrm{u} / \mathrm{l}, \mathrm{CK}-\mathrm{MB}=6300 \mathrm{w} / 1 \simeq 7,7 \%)$ é superponivel ao descrito em nossos pacientes, podendo ser atribuido apenas à rabdomiólise. A paciente apresentou intercorrências sérias, não observadas no curso habitual do acidente crotálico, em edema pulmonar já nas primeiras 24 horas após picada e hipotensão severa, a partir do 4\% dia, não havendo referências sobre as drogas utilizadas para a reversão desse quadro. Na própria discussão, ou autores colocam que a necrose em banda de contração presente na camada média das artérias coronárias é achado atribuído a vasoespasmo e este mecanismo por si só poderia explicar em parte as lesões do tipo isquêmico encontradas no miocárdio, considerando-se que a paciente esteve submetida a quadro de choque duradouro e irreversível.

$O$ músculo esquelético normal contém proporções semelhantes de fibras tipo I, IIa e IIb, com pequenas variações entre os músculos. Essas fibras diferem na sua atividade metabólica em relação às capacidades glicolíticas e oxidativas, o que se reflete no seu conteúdo enzimático. Assim, as fibras do tipo I (oxidativas) são mais ricas em CK-MB, LD1 e mioglobina; já as fibras tipo IIb (glicolíticas), contém maior proporção de LD5, e as fibras do tipo IIa, de atividade intermediária entre as anteriores, apresentam padrão de isoenzimas combinando as características das outras duas fibras 163543 .

Os achados de rabdomiólise observados na musculatura esquelética de pacientes picados por serpentes com peçonha portadora de atividade miotó- 
Cupo P. Marques MMA, Hering SE. Acidente crotálico na infância: aspectos clínicos, laboratoriais, epidemiológicos eabordagem terapéutica. Revista da Sociedade Brasileira de Medicina Tropical 24: 87-96, abr-jun, 1991

xica sistêmica revelam que dentro de um mesmo músculo, são encontradas fibras intactas rodeadas por fibras degeneradas ou necróticas 6821283037 . Esse mesmo padrão focal de comprometimento é encontrado na musculatura esquelética de corredores de maratona, em horas subsequentes à corrida 1949. Nessas circunstâncias, são também detectados aumentos nos níveis séricos de CK-MB, acompanhados ou não do aumento de LD1, sem evidências de comprometimento cardíaco 4154041 .

Sabe-se que a musculatura desses atletas é mais rica em CK-MB, o que é causado pelo processo constante de lesão/regeneração, bem como possui maior proporção de fibras do tipo I de maior conteúdo de CK-MB e de LDI5 10.

$O$ aparecimento da fração CK-MB imediatamente após o acidente crotálico exclui a regeneração muscular como sua fonte, bem como difere do padrão encontrado no infarto agudo do miocárdio em que há maior latência para sua deteç̧ão 2634 . Do mesmo modo, o aumento da fração LD1 não pode ser atribuído à hemólise, descartada em nossos pacientes pelos exames especificos realizados.

O comportamento das isoenzimas de CK e LD nos leva a concluir que a atividade miotóxica sistêmica da peçonha de Crotalus durissus terrificus possa ser especifica para as fibras musculares oxidativas do tipo I e/ou IIa, o que justificaria o perfil enzimático apresentado pelos pacientes, o comprometimento focal da musculatura esquelética detectado nas biópsias e a falta de agressão a outros tipos de fibras ou ao miocárdio. A análise histoquímica realizada em biópsias musculares de 2 pacientes vítimas de acidente crotálico demonstrou atrofia seletiva de fibras tipo I e múltiplos focos de necrose 21 , compativeis com os dados enzimáticos apresentados.

\section{Insuficiência renal aguda mioglobinúrica}

O diagnóstico de rabdomiólise é um dado importante para o clínico, pois deve alertá-lo para o possivel desenvolvimento de insuficiència renal aguda mioglobinúrica, que apresenta caracteristicas próprias.

O músculo esquelético, rico em creatinina, ácido úrico, potássio e fosfato, quando destruído ou lesado, libera essas substâncias para a circulação, em quantidades tais que podem ultrapassar os aumentos médios esperados nas demais formas de necrose tubular aguda. Assim, para a creatinina, são descritos aumentos séricos superiores a $2 \mathrm{mg} \%$ / 24 horas, enquanto que em outras etiologias, são observados incrementos de 0,5 a $1,0 \mathrm{mg} \%$ / 24 horas, caracterizando a IRA mioglobinúrica como de natureza hipercatabólica 17 .

Outra particularidade da IRA mioglobinúrica é a hipocalcemia acentuada que se observa na fase oligúrica, que em parte se deve aos níveis séricos elevados de fósforo e em parte, à deposição de cálcio em áreas de músculo lesado. Já durante a fase de recuperação da IRA pode ocorrer hipercalcemia, cuja etiologia parece depender de pelo menos dois fatores: mobilização de cálcio dos depósitos na musculatura lesada e aumento dos niveis de $1,25(\mathrm{OH}) \mathrm{D}_{3}$ circulante 1725 .

Deve ser ressaltado no entanto, que a mioglobinúria isoladamente não leva à necrose tubular aguda, sendo necessária a concomitância de outras condições como acidose metabólica e hipotensão e/ou hipovolemia, de ocorrência comum nos acidentes ofidicos. Em se tratando de Crotalus durissus terrificus, há o agravante do possivel efeito nefrotóxico direto de peçonhal ${ }^{3}$.

No sentido de prevenir a IRA do acidente crotálico, preconizamos em nossos pacientes a manutenção de um estado de hidratação que permita fluxo urinário de $2-3 \mathrm{ml} / \mathrm{kg} /$ hora. Na solução hidratante, acrescentamos bicarbonato de sódio na dose de 3 $\mathrm{mEq} / \mathrm{Kg}$ nas primeiras seis horas de hospitalização, permitindo-se acréscimos, se necessário, com controles de gasometria (o ideal seria atingir-se pH urinário ao redor de 6,5).

Diuréticos do tipo manitol, na dose de $0,5 \mathrm{~g} / \mathrm{kg}$, no sentido de prevenir a precipitação intratubular de mioglobina ou o edema das células tubulares, ou o furosemide, na dose de $1 \mathrm{mg} / \mathrm{kg} /$ dose, podem ser utilizados, desde que o paciente se encontre convenientemente hidratado.

Uma vez estabelecida a insuficiência renal, seu manejo é semelhante ao das demais, devendo apenas ser destacado que a IRA mioglobinúrica pode necessitar de métodos dialíticos mais precoces, dado sua natureza hipercatabólica.

\section{Soroterapia antiveneno ( $S A V)$}

Temos utilizado rotineiramente, desde 1979 , o SAV por via intravenosa, sem diluição, gota a gota, infundido durante um periodo máximo de 20 a 30 minutos, administrando previamente medicamentos capazes de impedir ou minimizar as possiveis manifestações anafiláticas ou anafilactóides que podem ocorrer com o uso de soros heterólogos.

A aplicação de testes cutâneos prévios foi abandonada definitivamente a partir de 1987, quando um estudo retrospectivo realizado em nosso serviço, analisando as manifestações de anafilaxia e testes de sensibilidade cutâneos, demonstrou o baixo valor preditivo e sensibilidade dos referidos testes, com o agravante de não serem totalmente isentos de riscos, além de retardarem o início da neutralização do veneno circulante ${ }^{13} 14$. É de fundamental importância no entanto que a equipe médica fique presente durante a infusão do $\mathrm{SAV}$, o que permitirá a rápida e adequada atuação na reversão de possível quadro de anafilaxia.

Em relação às crianças picadas por cascavel, observamos apenas manifestações cutâneas (mesmo 
Cupo P, Marques MMA, Hering SE. Acidente crotálico na infância: aspectos clínicos, laboratoriais, epidemiológicos e abordagem terapéutica. Revista da Sociedade Brasileira de Medicina Tropical 24: 87-96, abr-jun, 1991

Tabela 7 - Testes de sensibilidade intradérmico e manifestaf̧ões de anafilaxia observadas.

\begin{tabular}{lccc}
\hline Manifestaçóes de & \multicolumn{3}{c}{ Teste de sensibilidade } \\
\cline { 2 - 4 } Anafilaxia & Não realizado & Positivo & Negativo \\
\hline Sem reação & 9 & 3 & 3 \\
Apenas cutâneas & 3 & 1 & 1 \\
Gastrintestinais & 0 & 1 & 0 \\
\hline Total & 12 & 5 & 4 \\
\hline
\end{tabular}

com o uso de pré-medicação) em 5 pacientes e 1 episódio de cólica abdominal e vômitos em outro (Tabela 7). Foram observados 2 episódios de tremores generalizados não acompanhados de febre durante a infusão do SAV.

A dose de soro anticrotálico preconizada atualmente para o tratamento de acidente crotálico é aquela descrita na Tabela 2 , sendo idêntica para os adultos e as crianças: 10 ampolas para os acidentes considerados moderados e 20 ou mais, para os graves.

A rotina de atendimento de urgência ao paciente vitima de acidente ofidico em nosso hospital é a seguinte:

Rotina de atendimento de pacientes picados por animais peçonhentos atendidos no HC-FMR/USP

\section{5 minutos antes do $S A V$ :}

- dextroclorfeniramina: $0,08 \mathrm{mg} / \mathrm{kg}$ na criança e $5 \mathrm{mg}$ no adulto, i.m. ou i.v.

- hidrocortisona: $\quad 10 \mathrm{mg} / \mathrm{kg}$ na criança e 500 mg no adulto, i.v.

- cimetidine: $\quad 10 \mathrm{mg} / \mathrm{kg}$ na criança e 300 mg no adulto, i.v.

Apos, SAV sem diluição, goto a gota, durante 15 a 30 minutos, sob vigilância contínua da equipe médica.

\section{Manter preparados:}

- adrenalina (solução aquosa, milesimal)

- aminofilina

- oxigênio

- soluções salinas

- material de entubação.

\section{SUMMARY}

At the Hospital of Clinics of the Faculty of Medicine of Ribeirão Preto/USP during the years 1980-1989 21 children have been attended after rattlesnake bite: 16 severe and 5 with moderate envenomation. Four (20\%) developed acute tubular necrosis 2 necessitating dialysis. One patient died 13 days after the bite and grave complications including digestive hemorrhage and acute respiratory insuficiency. All patients preserved clinical laboratory and epidemiological characteristics of Crotalus durissus terrificus envenomation. We also comment on the correct management of such patients specially related to antivenin dosage and the prevention of acute tubular the most serious complication of such an accident.

Key-words: Crotalus durissus terrificus. Snake bites in children. Rhabdomyolysis. Myoglobinuria.

\section{REFERENCIAS BIBLIOGRÁFICAS}

1. Amaral CFS, Rezende NA, Pedrosa TMG, Silva OA, Pedroso ERP. Afibrinogenemia secundária a acidente ofidico crotálico (Crotalus durissus terrificus). Revista do Instituto de Medicina Tropical de São Paulo 30: 288292, 1988.

2. Amaral CFS, Silva OA, López M, Pedroso ERP. Afibrinogenemia following snake bite (Crotalus durissus terrificus). The American Journal of Tropical Medicine and Hygiene 29: 1453-1455, 1980.

3. Amorim MF, Mello RF. Nefrose do nefron intermediário no envenenamento crotálico humano. Estudo anátomo-patológico. Memórias do Instituto Butantan 24: 281316, 1952 .

4. Apple FS, McGue MK. Serum enzymes changes during marathon training. American Journal of Clinical Pathology 30: 479-499, 1969.

5. Apple FS, Rogers MA, Sherman WM, Costill DL, Hagerman FC, Ivy JL. Profile of creatine kinase isoenzymes in skeletal muscles of marathon runners. Clinical Chemistry 30: 413-416, 1984.

6. Azevedo-Marques MM, Cupo P, Coimbra TM, Hering SE, Rossi MA, Laure CJ. Myonecrosis, myoglobinuria and acute renal failure induced by South American rattlesnake (Crotalus durissus terrificus) envenomation in Brazil. Toxicon 23: 613-636, 1985.

7. Azevedo-Marques MM, Cupo P, Coimbra TM, Hering SE, Rossi MA, Oliveira JA. Mionecrose e insuficiência renal aguda mioglobinúrica após acidente crotálico. In: Livro de Programa e Resumos do XVIII Congresso da Sociedade Brasileira de Medicina Tropical J2, 1982.

8. Azevedo-Marques MM, Hering SE, Cupo P. Evidence that Crotalus durissus terrificus (South American rattlesnake) envenomation in humans causes myolysis rather than hemolysis. Toxicon 25: 1163-1168, 1987.

9. Barravieira B. Curso sobre Acidentes por Animais Peçonhentos: Acidentes por serpentes do gênero Crotalus. Arquivos Brasileiros de Medicina 64: 14-20, 1990.

10. Costill DL, Fink WJ, Pollok ML. Muscle fiber composition and enzyme activities of elite distance runners. Medicine and Science in Sports 8: 96-100, 1976.

11. Cupo P, Azevedo-Marques MM, Hering SE. Clinical and laboratory features of South American rattlesnake 
Cupo P, Marques MMA, Hering SE. Acidente crotálico na infância: aspectos clinicos, laboratoriais, epidemiológicos e abordagem terapéutica. Revista da Sociedade Brasileira de Medicina Tropical 24: 87-96, abr-jun, 1991

(Crotalus durissus terrificus) envenomation in children. Transactions of the Royal Society of Tropical Medicine and Hygiene 82: 924-929, 1988.

12. Cupo P, Azevedo-Marques MM, Hering SE. Acute myocardial infarction-like enzyme profile in human victims of Crotalus durissus terrificus envenoming. Transactions of the Royal Society of Tropical Medicine and Hygiene 84: 447-451, 1990.

13. Cupo P, Azevedo-Marques MM, Menezes JB, Hering SE. Validade do teste de sensibilidade intradérmico como rotina no atendimento de urgência ao paciente vitima de acidentes por animais peçonhentos - Acidentes ofidicos. Revista da Sociedade Brasileira de Toxicologia 2 (supl.): 5.1, 1989.

14. Cupo P, Hering SE, Menezes JB, Azevedo-Marques MM. Análise das reações ao uso endovenoso de soros antiofidicos. In: Anais do XXV Congresso Brasileiro de Toxicologia e II Seminário do Sistema Nacional de Informações Tóxico-Farmacológicas, Salvador resumo 17, 1987.

15. Diamond TH, Smith R, Goldman AP, Myburgh DP, Bloch JM, Visser F. The dilemma of the creatine kinase cardiospecific iso-enzyme (CK-MB) in marathon runners. South African Medical Journal 63: 37-41, 1983.

16. Dubowitz V. Histochemical aspects of muscle disease. In: Walton JN (ed) Disorders of voluntary muscle, 1th edition, Churchill Livingstone, Edinburgh p. 261-295, 1981.

17. Flamenbaum W, Gerth $\mathbf{M}$, Gross M, Kaufman J, Hamburger R. Acute renal failure associated with myoglobinuria and hemoglobinuria. In: Brenner BM, Lazarus JM (ed) Acute Renal Failure, 4th edition, WB Saunders, Philadelphia p. 269-282, 1983.

18. Furtado MA, Lester IA. Myoglobinuria following snake bite. Medical Journal of Australia 1: 674-676, 1968.

19. Hikida RS, Staron RS, Hagerman FC, Sherman WM, Costill DL. Muscle fiber necrosis associated with human marathon runners. Journal of the Neurological Sciences 59: 185-203, 1983

20. Hood VL, Johnson JR. Acute renal failure with myoglobinuria after tiger snake bite. Medical Journal of Australia 2: 638-641, 1975.

21. Jorge MT, Pereira JR, Benfatti Jr W, Ribeiro LA, Amato Neto V, Rassi IE, Bouabci AS. Comportamento de enzimas e alterações anatomopatológicas do músculo esquelético em pacientes picados por serpentes do gênero Crotalus. Revista da Sociedade Brasileira de Medicina Tropical 19(supl.): 29, 1986.

22. Karunaratne KE, Panabokke RG. Sea snake poisoningCase report. Journal of Tropical Medicine and Hygiene 75: 91-94, 1972.

23. Kitchens CS, Hunter S, Van Mierop LH. Severe myonecrosis in a fatal case of envenomation by the canebrake rattlesnake (Crotalus horridus atricaudatus). Toxicon 25: 455-458, 1987.

24. Leung FY, Henderson AR Thin-layer agarose electrophoresis of lactate dehydrogenase isoenzymes in serum: a note on the method of reporting and on the lactate dehydrogenase isoenzyme-1/isoensyme- 2 ratio in acute myocardial infarction. Clinical Chemeistry 25: 209-211, 1979.

25. Llach F, Felsenfeld AJ, Haussler MR. The pathophysiology of altered calcium metabolism in rhabdomyolysis- induced acute renal failure. The New England Journal of Medicine 305: 117-123, 1981.

26. Lott JA. Electrophoretic CK and LD isoenzyme assays in myocardial infarction. Laboratory Management 2: 2331, 1983.

27. Lott JA, Stang JM. Serum enzymes and isoenzymes in the diagnosis and differential diagnosis of myocardial ischemia and necrosis. Clinical Chemistry 26: 1241$1250,1980$.

28. Magalhāes RA, Ribeiro MMF, Rezende NA, Amaral CFS. Rabdomiólise secundária a acidente ofidico crotálico (Crotalus durissus terrificus). Revista do Instituto de Medicina Tropical de São Paulo 28: 228-233, 1986.

29. Marmor A, Kahana L, Alpan G, Grenadier E, Keidar S, Palant A. Creatine kinase isoenzyme MB (CK-MB) in acute coronary ischemia. American Heart Joumal 97: 574-577, 1979.

30. Marsden AT, Reid HA. Pathology of sea-snake poisoing. British Medical Journal 5235: 1290-1293, 1961.

31. Phillips RE, Theakston DG, Warrel DA, Galigedara $Y$, Abeysekera DTDJ, Dissanayaka P, Hutton RA, Aloysius DJ. Paralysis, rhabdomyolysis and haemolysis caused by bites of Russell's vipe (Vipera russelli pulchella) in Sri Lanka: failure of Indian (Haffkine) antivenom. The Quarterly Journal of Medicine 68: 691-716, 1988.

32. Raw I, Rocha MC, Esteves MI, Kamiguti AS. Isolation and characterization of a thrombin-like enzyme from the venom of Crotalus durissus terrificus. Brazilian Journal of Medical and Biological Research 19: 333-338, 1986.

33. Roberts R. Diagnostic assessment of myocardial infarction based on lactate dehydrogenase and creatine kinase isoenzymes. Heart and Lung 10: 486-506, 1981

34. Roberts R Enzymatic diagnosis of acute myocardial infarction. Chest 93(suppl): 3S-6S, 1988.

35. Rosalki SB. Creatine phosphokinase isoenzymes. Nature 207: 414, 1965.

36. Rosenfeld G. Symptomatology, pathology and treatment of snake bites is South America. In: Bücherl W, Bückley EE, Deulofeu V (ed) Venomous Animals and Their Venoms, 2th edition, Academic Press, New York p. 345384, 1971 .

37. Rossi MA, Peres LC, De Paola F, Cupo P, Hering SE, Azevedo-Marques MM. Electron microscopic study of systemic myonecrosis due to poisoning by tropical rattlesnake (Crotalus durissus terrificus) in humans. Archives of Pathology and Laboratory Medicine 113: 169-173, 1989.

38. Rowlands JB, Mastiglia FL, Kalulas BA, Hairnsworth D. Clinical and pathological aspects of a fatal case of mulga (Pseudechis australis) snakebite. Medical Journal of Australia 1: 226-230, 1969.

39. Siegel AJ, Dawson DM. Peripheral source of MB band of creatine kinase in alcoholic rhabdomyolysis. Nonspecificity of MB isoenzyme for myocardial injury in undiluted serum samples. The Joumal of the American Medical Association 244: 580-582, 1980.

40. Siegel AJ, Silverman LM, Evans WJ. Elevated skeletal muscle creatine kinase MB isoenzyme levels in marathon runners. The Journal of the American Medical Association 250: 2835-2837, 1983.

41. Siegel AJ, Silverman LM, Holman BL. Elevated creatine - kinase MB isoenzyme levels in marathon runners. 
Normal myocardial scintigrams suggest noncardiac source. The Journal of the American Medical Association 246: 2049-2051, 1981.

42. Siqueira JE, Higuchi ML, Nabut N, Lose A, Souza JK, Nakashima M. Lesão miocárdica em acidente ofidico pela espécie Crotalus durissus terrificus (cascavel). Relato de caso. Arquivos Brasileiros de Cardiologia 54: 323-325, 1990.

43. Sjödin B. Lactate dehydrogenase in human skeletal muscle. Acta Physiologica Scandinavica 436 (suppl): 532, 1976.

44. Sutherland SK, Coulter AR. Three instructive cases of tiger snake (Notechis scutatus) envenomation - and how a radioimmunoassay proved the diagnosis. Medical Journal of Australia 2: 177-180, 1977.

45. Tsung JS, Tsung SS. Creatine kinase isoenzymes in extracts of various human skeletal muscles. Clinical Chemistry 32: 1568-1570, 1986.

46. Tsung SH. Creatine kinase isoenzyme patterns in human tissue obtained at surgery. Clinical Chemistry 22: 173$175,1976$.

47. Urdal P, Urdal K, Stromme JH. Cytoplasmatic creatine kinase isoenzymes quantitated in tissue specimens obtained at surgery. Clinical Chemistry 29: 310-313, 1983.

48. Vasudevan G, Mercer DW, Varat MA. Lactic dehydrogenase isoenzyme determination in the diagnosis of acute myocardial infarction. Circulation 57: 1055-1057, 1978.

49. Warhol MJ, Siegel AJ, Evans WJ, Silverman LM. Skeletal muscle injury and repair in marathon runners after competition. American Journal of Pathology 118: 331-339, 1985. 